\title{
Burden of herpes zoster-associated chronic pain in Italian patients aged 50 years and over (2009-2010): a GP-based prospective cohort study
}

Hélène Bricout ${ }^{1 *}$, Emilia Perinetti ${ }^{2}$, Paolo Marchettini ${ }^{3,9}$, Pietro Ragni ${ }^{4}$, Carla Maria Zotti ${ }^{5}$, Giovanni Gabutti ${ }^{6}$, Antonio Volpi ${ }^{7}$ and Elisabetta Franco ${ }^{8}$

\begin{abstract}
Background: Post-herpetic neuralgia (PHN) is the most common complication in herpes zoster $(\mathrm{HZ})$ patients. Methods: We performed a longitudinal, prospective study in 108 general practices throughout Italy to assess how many immunocompetent patients aged $\geq 50$ years with newly diagnosed $\mathrm{HZ}$ develop $\mathrm{HZ}$-associated pain, its duration and management over 6 -months. HZ-associated pain was assessed by a direct question to the patient and by self-assessment of the worst pain felt in the previous two weeks on a visual analogue scale (VAS), a score $\geq 3$ was taken as pain. PHN was defined as pain reported during the study period persisting for $\geq 3$ months. Quality of life (QoL) was measured using the SF-12 questionnaire.

Results: At enrolment, 370 of the 413 patients (89.6\%) reported $\mathrm{HZ}$-associated pain which was still present in 20.6\% and $9.2 \%$ of patients after three and six months, respectively, despite many patients receiving recommended anti-viral therapy. The overall QoL scores were lower than those in healthy Italians of similar age; scores for patients with $\mathrm{HZ}$-associated pain were lower. The presence of $>50$ vesicles and VAS score $\geq 3$ at enrolment, and being male were significantly associated with PHN at three months.

Conclusions: These results suggest that $\mathrm{HZ}$ and PHN represent an important burden of disease in the elderly. There is a need for interventions that can prevent and reduce the burden of $\mathrm{HZ}$ to help improve the quality of life of the elderly. These data may be useful as baseline epidemiology data for the assessment of the impact of the VZV vaccine in Italy, after its implementation.
\end{abstract}

Keywords: Post herpetic neuralgia, Herpes zoster, Shingles, Pain, Varicella zoster virus, Vaccine-preventable diseases, Prospective study, Italy

\section{Background}

Varicella zoster virus (VZV) is a herpes virus that infects nearly all humans in temperate regions resulting in a highly contagious primary infection of varicella, usually in childhood [1]. After this infection, the virus remains latent in sensory ganglia until it is reactivated to cause herpes zoster (HZ) [2]. In Europe, almost all adults $(>95 \%)$ are healthy carriers of VZV following childhood varicella and are, therefore, at risk of developing HZ [3].

\footnotetext{
* Correspondence: hbricout@spmsd.com

'Epidemiological Department, Sanofi Pasteur MSD, Lyon, France

Full list of author information is available at the end of the article
}

The immune system declines with age (immunosenescence); the decline of VZV-specific T-cell-mediated immunity is thought to be involved in this reactivation [4]. The incidence and severity (number of vesicles, and pain intensity and duration) of $\mathrm{HZ}$ increase with age, but it is difficult to predict who will develop HZ $[5,6]$. Although patients with treatment- or disease-associated immunosuppression are at higher risk for $\mathrm{HZ}, 90 \%$ of patients with $\mathrm{HZ}$ are immunocompetent. Other risk factors include sex, ethnicity, genetic susceptibility, familial history of HZ, mechanical trauma, psychological stress, depression and diabetes [7-9]. 
Herpes zoster is characterized by a, usually painful, unilateral vesicular rash, generally limited to a single dermatome, corresponding to the sensory ganglion from which the latent VZV was reactivated [10]. The most frequent localization $(>50 \%)$ is thoracic, followed by cranial, including the ophthalmic division of the trigeminal nerve; the incidence of this latter localization increases with age [11].

Pain may occur during three distinct phases of the disease:

prodromal pain: often occurs prior to rash onset; acute pain or neuritis: begins with the rash and usually disappears within 2 to 4 weeks;

chronic pain i.e. post-herpetic neuralgia (PHN): most commonly defined as pain occurring or persisting for $\geq 3$ months after rash onset.

HZ-associated pain is debilitating and often has a substantial, negative impact on patients' normal life and health, particularly among the elderly whose activities and basic tasks of daily living can be impaired and anxiety and depression can occur $[12,13]$. In addition, when PHN occurs, pain management is difficult and patients suffer from important side effects [14]. Treatment with antiviral agents within 72 hours of rash onset for seven days is recommended in some patient groups to accelerate rash healing and to limit the severity and duration of pain [15]. However, observational studies in France, Italy, the Netherlands and the UK and a meta-analysis gave heterogeneous results [16-20].

The annual $\mathrm{HZ}$ incidence is similar throughout Europe, increasing with age from around 1-4/1 000 in adults aged $<50$ years to about $7-8 / 1000$ in those $\geq 50$ years, up to $10 / 1000$ at $>80$ years [21]. After the introduction of antivirals drugs, about $10 \%$ to $30 \%$ of patients aged $\geq 50$ years with HZ develop PHN in Europe [22]. Most studies estimating the percentage of patients with $\mathrm{HZ}$ who develop PHN are retrospective. In addition, there is no consensus for the definition of PHN making comparisons between studies difficult [22].

In Italy, there are insufficient data on the burden of $\mathrm{HZ}$ and PHN because there is no HZ-specific national surveillance system. In one nationwide study the annual incidence of general practitioner (GP) visits for $\mathrm{HZ}$ was $4.1 / 1000$ persons aged $\geq 15$ years; $19.6 \%$ presented with PHN and $26.1 \%$ presented $\geq 1$ complications [23]. One study in 2004 in the Piedmont region reported an overall $\mathrm{HZ}$ incidence rate of 1.59/1 000 inhabitants and a hospitalization incidence rate of 0.12/1 000 [24]. In another study that analysed data from four regions in Italy, the $\mathrm{HZ}$ incidence in adults aged $\geq 50$ years was $6.6 / 1$ 000 , and $9.4 \%$ and $7.2 \%$ of the patients had PHN at 1 month and 3 month, respectively [25]. Another study that analysed data from 1999 to 2005 reported a mean annual number of $4503 \mathrm{HZ}$ hospitalisations and 543 dayhospitalisations; $62 \%$ of patients were $>65$ years [26].

In the perspective of a VZV vaccine to prevent and reduce the severity of $\mathrm{HZ}$ becoming available in Europe, it was decided to obtain baseline data on the occurrence of PHN in a multicenter, longitudinal, prospective, observational study involving general practitioners (GPs) throughout Italy, the HER.O.E.S. Study - HERpes zoster Outcome: Epidemiological Study. The primary objective was to assess the percentage of patients with $\mathrm{HZ}$ that have HZ-associated chronic pain and its duration.

\section{Methods}

This study was conducted in compliance with the Declaration of Helsinki (Seoul revision; 2008), Good Epidemiological Practice Guidelines and Italian national regulations $[27,28]$. The protocol and study documentation were approved by Ethics Committee for each local health unit (See Table 1).

\section{Study objectives}

The co-primary objectives of the six-month study were:

to assess the percentage of patients with $\mathrm{HZ}$ who developed HZ-associated chronic pain and how long the pain lasted.

to collect disease management data from diagnosis to resolution of the acute symptoms, and data on the management of HZ-related pain.

The secondary objectives were to assess quality of life (QoL) in the patients with HZ/PHN using the SF-12 instrument and to assess HZ-related pain intensity using a visual analogue scale (VAS). We also recorded the presence of clinical variables that have been identified as risk factors for $\mathrm{HZ}$ and assessed the patients' care pathway and their disease progression during the study period.

\section{Study design}

Patients aged $>50$ years old with a new clinical diagnosis of $\mathrm{HZ}$, who were immunocompetent and who signed an informed consent form were enrolled in the study. Each patient was expected to attend four visits at 0,1 ( \pm 15 days), 3 ( \pm 21 days) and 6 ( \pm 30 days) months. Patients could be excluded from the analysis for one visit for non-respect of the time window, but included in the analysis for a subsequent visit, if it occurred within the time window.

At the initial visit (V0), descriptive information was collected: socio demographic data, clinical description, medical history. The patients were asked if they had HZassociated pain at the visit and their quality of life was assessed using the physical component summary (PCS-12) 
Table 1 List of local ethics committees that approved the protocol and study documentation

\begin{tabular}{|c|c|c|}
\hline Local health unit & IRB/IEC name & IRB/IEC address \\
\hline \multirow[t]{2}{*}{ Alessandria } & Comitato Etico & Via Venezia, 16 \\
\hline & Azienda Osped. SS. Antonio e Biagio e Cesare Arrigo & 15100 Alessandria \\
\hline \multirow[t]{3}{*}{ Asolo } & Comitato Etico & Borgo Cavalli, 42 \\
\hline & Azienda ULSS N. 9 di & 31100 Treviso \\
\hline & Treviso & \\
\hline \multirow[t]{3}{*}{ Asti } & Comitato Etico & Via Venezia, 16 \\
\hline & Azienda Ospedaliera SS. Antonio e Biagio & 15100 Alessandria \\
\hline & e Cesare Arrigo & \\
\hline \multirow[t]{3}{*}{ Bologna } & Comitato Etico & Via Gramsci, 12 \\
\hline & Azienda USL di Bologna & 40121 Bologna \\
\hline & Dipartimento Farmaceutico & \\
\hline \multirow[t]{2}{*}{ Brindisi } & COMITATO ETICO & Via Napoli, 8 \\
\hline & ASL n. 1 di BRINDISI & 72100 Brindisi \\
\hline \multirow[t]{3}{*}{ Bussolengo } & Comitato etico & Via Salvo D’Acquisto, 7 \\
\hline & Provincia di Verona Azienda ULSS 20 di Verona c/o Dipartimento & 37122 Verona \\
\hline & Farmaceutico & \\
\hline \multirow[t]{2}{*}{ Carbonia } & Comitato Etico & Via Dalmazia, 83 \\
\hline & ASL di Carbonia & 09013 Carbonia \\
\hline \multirow[t]{3}{*}{ Catanzaro } & Comitato Etico & Via Vinicio Cortese, 25 \\
\hline & Azienda Sanitaria & 88100 Catanzaro \\
\hline & Provinciale di Catanzaro & \\
\hline \multirow[t]{3}{*}{ Ferrara } & Comitato Etico & Corso Giovecca, 203 \\
\hline & c/o Ufficio Ricerche e Innovazioni & 44100 Ferrara \\
\hline & Azienda Ospedaliero, Universitaria di Ferrara & \\
\hline \multirow[t]{2}{*}{ Genova } & Comitato Etico & Via Bertani, 4 \\
\hline & Asl 3 Genovese & 16125 Genova \\
\hline \multirow[t]{2}{*}{ Grosseto } & Comitato Etico & Via Genova, 6/D \\
\hline & c/o U.O. Farmaceutica Territoriale - Azienda USL n. 9 di Grosseto & 58100 Grosseto \\
\hline \multirow[t]{2}{*}{ Lecce } & Comitato Etico & Via Miglietta, 5 \\
\hline & ASL di Lecce & 73100 Lecce \\
\hline \multirow[t]{2}{*}{ Milano } & Comitato Etico ASL Città di Milano & Via Statuto, 5 \\
\hline & c/o Servizio Farmaceutico & 20121 Milano \\
\hline \multirow[t]{2}{*}{ Napoli/5 } & Comitato Etico & Piazza San Giovanni \\
\hline & ASL Napoli 3 Sud & 80031 Brusciano (NA) \\
\hline \multirow[t]{2}{*}{ Pavia } & Comitato Etico & Via Indipendenza, 3 \\
\hline & Asl Provincia di Pavia & 27100 Pavia \\
\hline \multirow[t]{2}{*}{ Pescara } & Comitato Etico & Via Fonte Romana, 8 \\
\hline & ASL di Pescara & 65100 Pescara \\
\hline \multirow[t]{2}{*}{ Ragusa } & Comitato Etico & Piazza Igea, 2 \\
\hline & Azienda USL 7 di Ragusa & 97100 Ragusa \\
\hline \multirow[t]{2}{*}{ Roma/C } & Comitato Etico & Piazzale Umanesimo, 10 \\
\hline & c/o Direzione Amministrativa Ospedale Sant'Eugenio & 00144 Roma \\
\hline \multirow[t]{2}{*}{ Roma/H } & Comitato Etico & Borgo Garibaldi, 12 \\
\hline & ASL Roma H di Albano & 00041 Albano Laziale (RM \\
\hline
\end{tabular}


Table 1 List of local ethics committees that approved the protocol and study documentation (Continued)

\begin{tabular}{lll}
\hline & Laziale & \\
Teramo & Comitato Etico & Circonvallazione Ragusa, 1 \\
Torino/1 & C/o Servizio Farmaceutico Territoriale - ASL 106 di Teramo & 64100 Teramo \\
& Segreteria Tecnico-Scientifica del Comitato Etico & Corso Svizzera 185 BIS \\
Treviso & ASL TO 2 & 10149 Torino \\
& Comitato Etico & Borgo Cavalli, 42 \\
Varese & Azienda ULSS N. 9 di & 31100 Treviso \\
& Treviso & Via Ottorini Rossi, 9 \\
Verona & Segreteria del Comitato Etico c/o Direzione Sanitaria ASL della & 21100 Varese \\
& Provincia di Varese & Via Salvo D’Acquisto, 7 \\
Vibo Valentia & Comitato Etico & 37122 Verona \\
& Provincia di Verona Azienda ULSS 20 di Verona c/o Dipartimento Farmaceutico & Via Dante Alighieri, Palazzo \\
& Comitato Etico & ex
\end{tabular}

Note: sites of Genova, Pavia, Alessandria, Asolo were not activated and did not enrol patients.

and the mental component summary (MCS-12) scores from the SF-12 questionnaire. The scores ranged from 0 (lowest level of health) to 100 (highest level of health) [29]. A score of $<50$ indicates a below-average health status. The level of pain was assessed using a visual analogue scale (VAS) for the worst pain felt during the previous two weeks, with scores ranging from 0 ('no pain') to 10 ('worst pain imaginable'). A VAS score of $\geq 3$ was considered to be correlated with pain interfering with activities of daily living [30]. At each follow-up visit the presence of HZ-associated pain, the level of pain using the VAS and quality of life (QoL) scales were assessed. In addition, data on the clinical evolution and the health care resources used were collected.

The presence of allodynia, itching, paresthesia and malaise were all assessed by the physicians during the clinical examination at corresponding study visit. Data were collected using an electronic case report form (eCRF) which enabled a real-time quality control of the data at entry. In addition, a clinical research assistant telephoned the GPs monthly and also performed ad hoc monitoring visits during the study.

\section{Assessment of HZ-associated pain}

In HEROES, PHN (primary outcome) was defined as pain that persisted for more than three months after rash onset assessed by the patient replying 'yes' at a study visit when asked by the GP about the presence of HZ-associated pain. This assessment mode was chosen to be pragmatic, since physicians do not use tools to measure pain systematically. For the secondary outcome, HZ-associated pain was assessed with a score $\geq 3$ on the VAS, reflecting the worst pain the patient had felt during the two-weeks prior to the visit.

\section{Sample size calculation}

Based on information obtained from a questionnaire survey conducted on 317 GPs throughout Italy in 2008 that collected data on the number of patients with $\mathrm{HZ}$ they treated annually and how many had PHN, and other published data, [31-33] we assumed that between $15 \%$ and $40 \%$ of patients with $\mathrm{HZ}$ would have HZassociated pain. Thus, with a threshold of $\mathrm{p}=0.05$ and a pain incidence of $40 \%$, it was estimated that we needed to enrol 400 patients to guarantee a precision of $\pm 4.8 \%$. We decided to enrol 500 patients to allow for $20 \%$ erroneously-enrolled patients.

\section{Statistical analyses}

The descriptive analyses were performed with SAS (Statistical Analysis System), V9.2. The recorded or derived variables were summarized as frequencies (absolute or relative) or means or medians with their associated distribution (number of observations, mean, standard deviation, median, minimum, maximum). For all clinically-relevant variables, 95\% confidence intervals (CIs) were calculated. Analyses were stratified on gender, age group (50-59, $60-69$ and $\geq 70$ ), and presence of pain at the respective visit.

Variables present at the initial visit associated $(\mathrm{p}=0.25)$ with PHN at 3-months in univariate analyses were included in a multivariate regression model to identify PHN predictive factors $(\mathrm{p} \leq 0.05)$. The fit of the final model was assessed using the Hosmer and Lemeshow goodness-of-fit 
test. The estimated $\beta$ coefficients and the corresponding 95\% CIs were calculated. Odds ratios and the corresponding 95\% CIs were also calculated.

\section{Results}

\section{Patient population}

A total of 108 of the 147 GPs who accepted to participate in the study included at least one patient. These 108 GPs were from 21 local health units localized in 12 Italian regions. Their regional distribution was similar to the national distribution (data not shown). They enrolled 435 patients with a new diagnosis of HZ from 27 March 2009 to 5 July 2010 of whom 413 were included in the study (Figure 1).The majority of the GPs $(72.2 \%)$ respected the time windows for all their patients' follow-up visits.

The patients were aged $67.9 \pm 10.7$ years old and $64.2 \%$ were women (Table 2). Almost half (46.7\%) of the study population were aged $\geq 70$ years. The majority $(81.4 \%)$ lived with their family; about $25 \%$ were working. Most patients $(90.3 \%)$ had been followed by their GP for $>5$ years with a mean of 8.2 visits during the previous 12 months.
More than $60 \%$ of the patients presented $\geq 1$ chronic condition (diabetes, chronic cardiovascular disease or chronic respiratory diseases); the percentage increased with age.

\section{Clinical characteristics and treatment of $\mathrm{HZ}$}

The mean delay from $\mathrm{HZ}$ prodrome and rash onset to consultation was 4.5 days and 3 days, respectively. This delay was longer in older patients; delay since prodrome: 3.7 days for those aged 50-59; 4.3 days for those aged 60-69 and 5.1 days for those aged $\geq 70$ and since rash onset: 2.3 days for those aged $50-59 ; 2.7$ days for those aged $60-69$ and 3.2 for those aged $\geq 70$. All patients $(100 \%)$ presented with a rash and $77 \%$ had $<50$ vesicles. The rash was mainly localized in the thoracic dermatome area (59.1\%) followed by cervical (15.0\%), lumbar (13.8\%), cranial (12.6\%) and sacral segment (11.1\%) dermatome areas, respectively (Table 2 ).

Among the patients presenting with pain at the initial visit, $59.7 \%$ had allodynia, $74.3 \%$ itching and $58.9 \%$ paresthesiae (Table 3). Many patients who reported pain during the study follow-up visits still had allodynia (49.2\%, 56.2\%

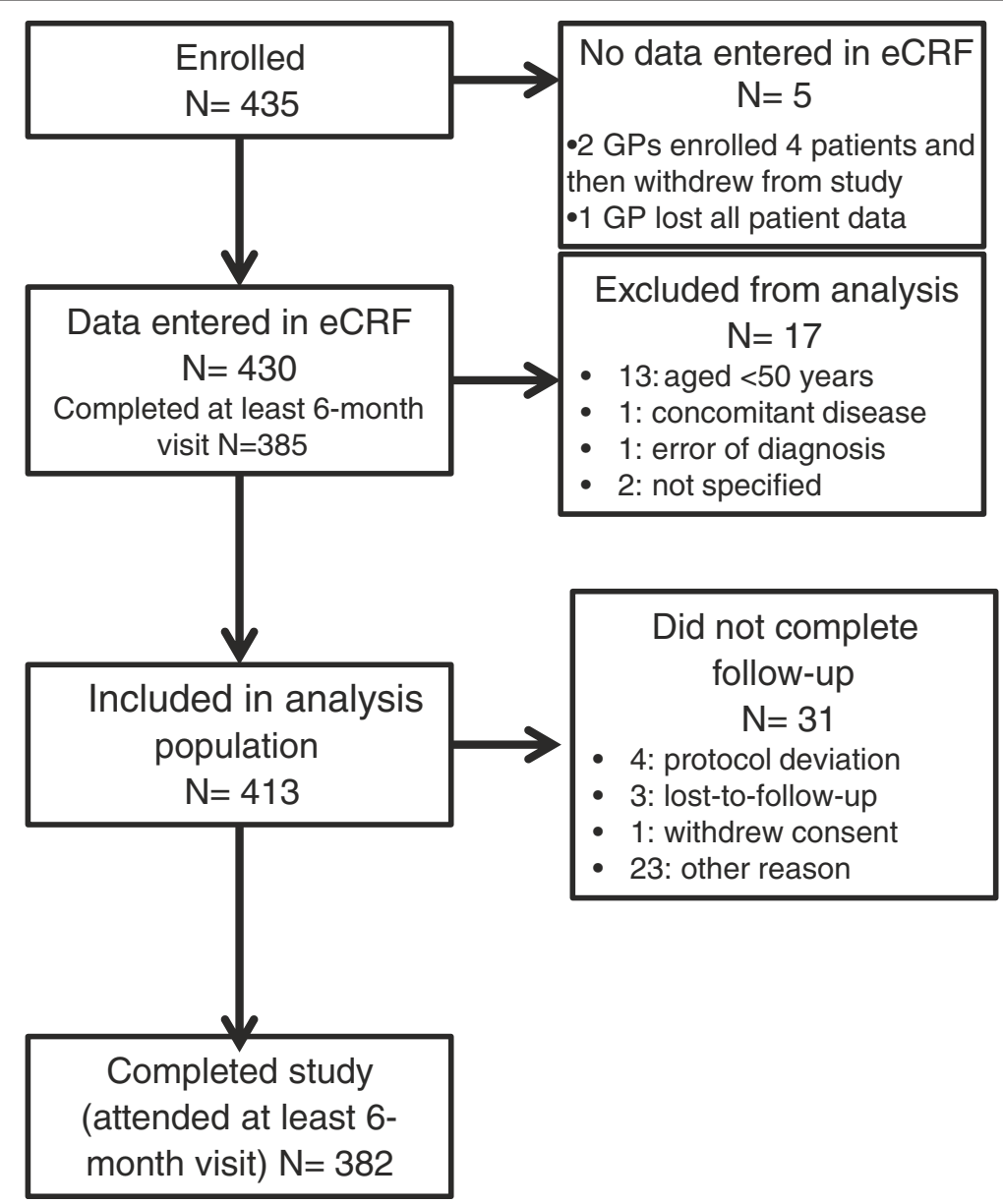

Figure 1 Disposition of included patients. 
Table 2 Baseline characteristics of included subjects

\begin{tabular}{|c|c|c|c|c|c|c|}
\hline \multirow[t]{2}{*}{ Number of patients (\%) } & $50-59$ & $60-69$ & $\geq 70$ & Males & Females & Total \\
\hline & $107(25.9)$ & $113(27.4)$ & $193(46.7)$ & $148(35.8)$ & $265(64.2)$ & $413(100)$ \\
\hline Age, years, mean $\pm S D$ & $54.5 \pm 2.8$ & $64.4 \pm 2.9$ & $77.4 \pm 6.2$ & $68.3 \pm 11.0$ & $67.7 \pm 10.6$ & $67.9 \pm 10.7$ \\
\hline Gender, \%, M/F & $33.6 / 66.4$ & $33.6 / 66.4$ & $38.3 / 61.7$ & - & - & $35.8 / 64.2$ \\
\hline \multicolumn{7}{|l|}{ Employment status $\mathbf{n}(\%)$} \\
\hline Worker & 79 (73.8) & $23(20.4)$ & $2(1.0)$ & $46(31.1)$ & $58(21.9)$ & $104(25.2)$ \\
\hline Retired & $11(10.8)$ & $76(67.3)$ & $184(95.3)$ & $102(68.9)$ & $169(63.8)$ & $271(65.6)$ \\
\hline Other & $17(15.9)$ & $14(12.4)$ & $7(3.6)$ & - & $38(14.3)$ & $38(9.2)$ \\
\hline \multicolumn{7}{|l|}{ Medical history, n (\%) } \\
\hline Diabetes & $14(13.1)$ & 19 (16.8) & $39(20.2)$ & $25(16.9)$ & $47(17.7)$ & $72(17.4)$ \\
\hline Type 1 & $3(2.8)$ & 0 & $3(1.6)$ & $4(2.7)$ & $2(0.8)$ & $6(1.5)$ \\
\hline Type 2 & $11(10.3)$ & 19 (16.8) & $36(18.7)$ & $21(12.2)$ & $45(17.0)$ & $66(16.0)$ \\
\hline Chronic cardiovascular diseases & $26(24.3)$ & $61(54.0)$ & $139(72.0)$ & $84(56.8)$ & $142(53.6)$ & $226(54.7)$ \\
\hline Chronic respiratory diseases & $6(5.6)$ & $13(11.5)$ & $33(17.1)$ & $27(18.2)$ & $25(9.4)$ & $52(12.6)$ \\
\hline Other relevant diseases & $29(27.1)$ & $51(45.1)$ & $100(51.8)$ & $60(40.5)$ & $120(45.3)$ & $180(43.6)$ \\
\hline \multicolumn{7}{|l|}{ Rash localization n (\%) } \\
\hline Cranial & $16(15.0)$ & $14(12.4)$ & $22(11.4)$ & $15(10.1)$ & $37(14.0)$ & $52(12.6)$ \\
\hline Cervical & $19(17.8)$ & $23(20.35)$ & $20(10.4)$ & $19(12.8)$ & $43(16.2)$ & $62(15.01)$ \\
\hline Thoracic & $61(57.0)$ & $63(55.8)$ & $120(62.2)$ & $92(62.2)$ & $152(57.4)$ & $244(59.1)$ \\
\hline Lumbar & $15(14.0)$ & $12(10.62)$ & $30(15.5)$ & $22(14.9)$ & $35(13.2)$ & $57(13.8)$ \\
\hline Sacral & $12(11.2)$ & $11(9.73)$ & $23(11.9)$ & $17(11.5)$ & $29(10.9)$ & $46(11.1)$ \\
\hline \multicolumn{7}{|l|}{ Number of vesicles, $\mathbf{n}(\%)$} \\
\hline None & $5(4.7)$ & $4(3.5)$ & $6(3.1)$ & $6(4.1)$ & $9(3.4)$ & $15(3.6)$ \\
\hline Less than 50 & $83(77.6)$ & $88(77.9)$ & $147(76.2)$ & $112(75.7)$ & $206(77.7)$ & $318(77.0)$ \\
\hline More than 50 & $18(16.8)$ & 21 (18.6) & $40(20.7)$ & $30(20.3)$ & 49 (18.5) & $79(19.1)$ \\
\hline \multicolumn{7}{|l|}{ SF-12 (mean, SD) } \\
\hline Physical Health Score (PCS-12) & $42.7 \pm 7.6$ & $41.4 \pm 8.0$ & $37.6 \pm 9.2$ & $41.5 \pm 8.4$ & $39.4 \pm 8.8$ & $40.1 \pm 8.7$ \\
\hline Mental Health Score (MCS-12) & $41.9 \pm 10.8$ & $42.6 \pm 10.0$ & $41.0 \pm 10.9$ & $45.2 \pm 10,0$ & $39.8 \pm 10.4$ & $41.7 \pm 10.6$ \\
\hline
\end{tabular}

and $52.9 \%$ at the 1-month, 3-month and 6-month visits, respectively) whereas there was a decrease in the percentage of patients with paresthesiae and itching.

Most of the patients (91.5\%) received an oral antiviral (acyclovir: $\mathrm{n}=149$; brivudin: $\mathrm{n}=103$; valacyclovir: $\mathrm{n}=86$; famciclovir: $n=42$ ) for a median duration of 6.0 days. Oral antiviral treatment was initiated a median of two days after rash onset (mean $=3.4$ days); $70 \%$ of the patients initiated oral antiviral treatment within three days after rash onset. Topical antiviral treatment was administered to $9.4 \%$ of patients (acyclovir: $\mathrm{n}=37$; tromantadine hydrochloride: $\mathrm{n}=2$ ).

Only 23\% of the patients received pain therapy for a median duration of 12.5 days (mean $=3$ days); analgesics (codeine-paracetamol, oxycodone, paracetamol, tramadol, tramadol-paracetamol) $(\mathrm{n}=48)$, nonsteroidal antiinflammatory drugs (NSAID)s $(\mathrm{n}=36)$, anti-epileptics $(\mathrm{n}=29)$ or psycho-analeptics $(\mathrm{n}=12)$.
Among the 104 patients who worked at the initial visit, 36 took sick-leave due to their HZ episode for: 1 to 5 days (53\%); 6 to 10 (33\%); and more than 10 days (14\%). At the 1-month visit, 33 patients reported that they had taken sick-leave, 2 at the 3 -month visit and 1 at the 6-month visit.

About $12 \%$ of the patients $(n=52)$ consulted $\geq 1$ specialist during the study (mainly a dermatologist, neurologist or ophthalmologist). None of the patients were hospitalised due to $\mathrm{HZ}$.

\section{Herpes zoster-associated pain}

Overall, 370/413 (89.6\% [86.2-92.3]) patients reported HZ-associated pain at the initial visit with a mean score of $5.8 \pm 2.4$ (Table 3 ). Among the 353 patients who completed the three-month visit $73(20.6 \%$ [16.5-25.2]) still reported pain, satisfying our definition for $\mathrm{PHN}$; the percentage increased with age (14.3\% of those aged $50-59$ 
Table 3 Assessment and characteristics of the HZ-associated pain and quality of life scores at each study visit

\begin{tabular}{|c|c|c|c|c|}
\hline & \multicolumn{4}{|l|}{ Visit } \\
\hline & Enrolment & 1 month & 3 months & 6 months \\
\hline Number of patients who completed the visit & 413 & 390 & 353 & 368 \\
\hline \multicolumn{5}{|l|}{ Patients reporting pain at the respective visit } \\
\hline Number of patients & 370 & 193 & 73 & 34 \\
\hline Mean VAS score for patients reporting pain \pm SD & $5.8 \pm 2.4$ & $4.4 \pm 2.3$ & $3.7 \pm 2.0$ & $3.7 \pm 2.3$ \\
\hline \multicolumn{5}{|l|}{ Main characteristics of $\mathrm{HZ}$-associated pain (\%) } \\
\hline Allodynia & 59.7 & 49.2 & 56.2 & 52.9 \\
\hline Itching & 74.3 & 27.5 & 21.9 & 17.7 \\
\hline Paresthesia & 58.9 & 49.7 & 52.1 & 38.2 \\
\hline Malaise & 20.8 & 14.0 & 13.7 & 8.8 \\
\hline \multicolumn{5}{|l|}{ Quality of life score (SF12) } \\
\hline Mean PCS-12 score \pm SD & $39.2 \pm 8.4$ & $37.7 \pm 8.3$ & $40.1 \pm 8.4$ & $39.0 \pm 9.3$ \\
\hline Mean MCS-12 score \pm SD & $41.6 \pm 10.4$ & $39.3 \pm 10.4$ & $39.6 \pm 9.8$ & $39.4 \pm 10.6$ \\
\hline \multicolumn{5}{|c|}{ Patients with a VAS score $\geq 3$ at the respective visit } \\
\hline Number of patients & 308 & 175 & 71 & 50 \\
\hline Mean VAS score among these patients & $6.4 \pm 1.9$ & $5.2 \pm 1.9$ & $4.9 \pm 1.8$ & $5.4 \pm 2.1$ \\
\hline
\end{tabular}

years, $20.2 \%$ of those aged $60-69$ years and $24.5 \%$ of those aged $\geq 70$ years) (Figure $2 \mathrm{~A}$ ). PHN was still present in 34 of the 368 patients at the six-month visit (9.2\% [6.5-12.7]). The prevalence of pain at the month 3 and 6 visits was higher among patients who reported pain at the one-month visit (Figure 3). There was a non-statistically significant trend for more men than women to report pain at the one- and three-month visits (all p values $>0.05$ ).

The mean VAS score for patients who reported pain at each visit decreased from 5.8 (median 6) at enrolment to 3.7 (median 3 ) at the six-month visit. The percentage of patients with a VAS score $\geq 3$ was $81.7 \%$ [77.6\% - 85.4\%] at the initial visit; $49.7 \%$ [44.5\% - 54.9\%] at the 1 -month visit; $22.4 \%[18.1 \%-27.2 \%]$ at the 3 -month visit and $15.2 \%$ [12.0\% - 20.0\%] at the 6-month visit (Figure 2B).

\section{Predictive factors for persistent $\mathrm{HZ}$-associated pain}

The results from the univariate analyses showed that the presence at the initial visit of $>50$ vesicles, allodynia, a VAS score $\geq 3$, the PCS-12 score, the presence of diabetes or chronic cardiovascular disease or respiratory disease, age, a rash localized on the lumbar dermatome, being male and the MCS-12 score were potential predictive factors for the persistence of pain at three months (PHN). Multivariate analysis, including these variables, showed that the presence of $>50$ vesicles $(\mathrm{OR}=2.595[1.267-5.314])$, a VAS score $\geq 3$ $(\mathrm{OR}=4.599$ [1.181-17.907]) and being male $(\mathrm{OR}=2.017$ [1.006-4.042]) were significantly associated with PHN $(\mathrm{p}<0.05)$ (Table 4).

\section{Quality of life assessment}

At the initial visit, the patients' mean SF-12 scores were below the mean value of 50 (PCS-12 score $=40.1 \pm 8.7$, MCS-12 score $=41.7 \pm 10.6-$ Table 2 ). Both scores were lower in women and in older patients, particularly the PCS-12 score; patients without pain present at the visit had higher scores than those with pain. The mean PCS-12 and MCS scores in the study were lower than those in the healthy Italian population (Table 2) [34]. During the study, the PCS-12 and MCS-12 scores in patients presenting with pain at the respective visit did not vary, except for a small decrease in the MCS-12 score (Table 3).

\section{Discussion}

The results from this prospective study, performed in a large network of GPs in Italy, show that patients aged $\geq 50$ years report that $\mathrm{HZ}$ is painful, it has a negative impact on their QoL, working patients need to take sick leave and increasing age is a risk factor for severity. The incidence of PHN was high $(20.6 \%$ at three-months and $9.2 \%$ at 6 -months), although the majority of patients received antiviral treatment.

All the patients included had a rash even if the presence of rash was not an inclusion criterion, suggesting that the GPs diagnosed HZ based on the presence of the typical rash. We cannot exclude erroneous diagnosis since there was no laboratory confirmation. In the pivotal $\mathrm{HZ}$ vaccine clinical trial in adults, $5-6 \%$ of the clinical diagnoses were not confirmed in the laboratory [35]. Similarly, a prospective study of $\mathrm{HZ}$ diagnoses by GPs found $17 \%$ of diagnoses to be incorrect [36]. 
A)

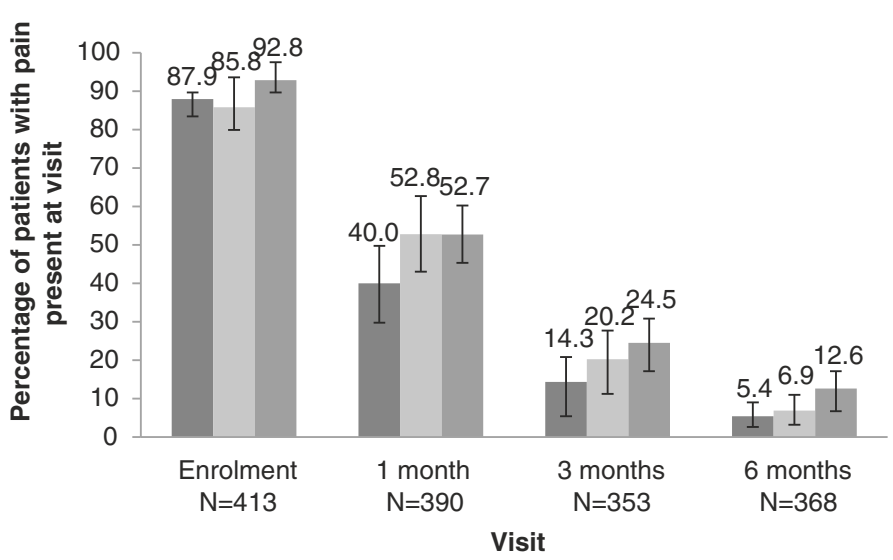

B)

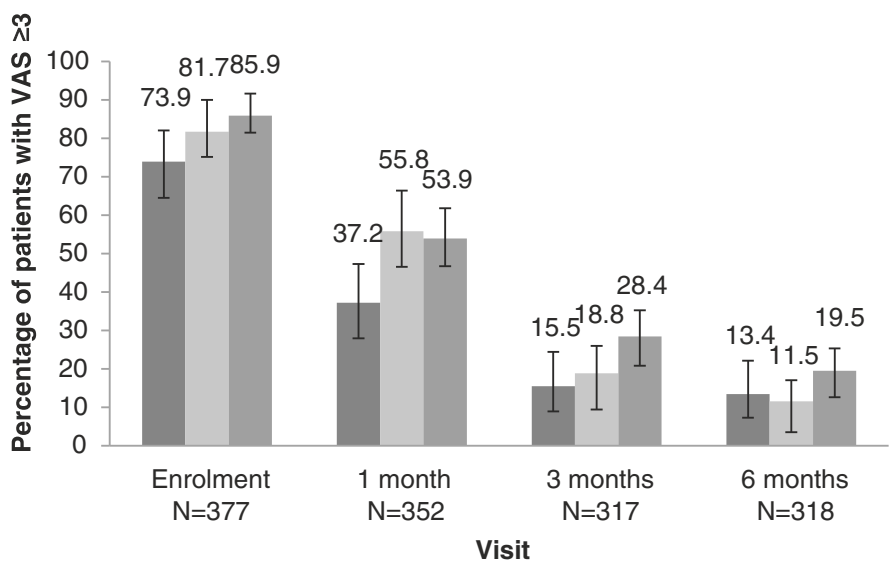

Figure 2 Percentage of patients with HZ-associated pain by age group (50-59; 60-69 and $\geq 70$ ) and by visit A) presence of pain at visit and B) pain in the previous two weeks with a VAS score $\geq 3$.

In HEROES, the patients enrolled do not seem to have suffered from severe disease as none were hospitalised. In Italy, the $\mathrm{HZ}$ hospitalization rate has been reported to be 5.6 per 100,000 patients and 10.3 per 100,000 for those with PHN [25]. The study was designed to have sufficient power to estimate the percentage of patients with $\mathrm{HZ}$-associated pain, but was insufficient to detect $\mathrm{HZ}$ hospitalization. It is possible that patients with more severe disease may have consulted a specialist or were hospitalized directly. In addition, the low rate of consultations with specialists $(12.3 \%$ during the six-month study) and the delay of about three days between rash onset and the GP visit suggest that the patients included in this study were suffering from non- severe to moderately-severe disease.

We observed a higher incidence of HZ-associated pain than that observed in the placebo group of the pivotal study (12\% for PHN 3 months); however, the percentage of men was higher in the pivotal study and the subjects were older ( $\geq 60$ years) so the age distribution was different [35]. In a French study, 11.6\% of patients with HZ suffered from HZ-associated pain at 3-months, as declared by the patients whereas in a UK study there were about $27 \%$ of patients who suffered from PHN [16,32]. These differences could be due to different access to healthcare and pain management or the method used to assess the HZ-associated pain. This last point is highlighted by the slightly different estimates for HZ-associated pain for the primary and secondary outcomes we observed in our study. Additionally, the VAS score was missing for $10.2 \%$ and $13.6 \%$ of patients at the 3 - and 6-month visits, respectively; we cannot exclude that patients who suffered more from pain were more likely to complete the VAS score.

The percentage of patients with PHN reported in retrospective database studies ranged from $6.9 \%$ to $32 \%$ [21,25,33,37-39]. Retrospective studies using International Classification of Disease (ICD) codes to extract data from databases do not always provide a reliable estimate of $\mathrm{HZ}$ and PHN incidences because of possible miscoding and under-coding. Additionally, the absence of a specific ICD code for PHN makes database extraction less reliable for this endpoint. The prospective design of our study, including three follow-up visits, enabled a better diagnosis of PHN than retrospective studies. Nevertheless, even if the actual estimates were different, the studies also generally 


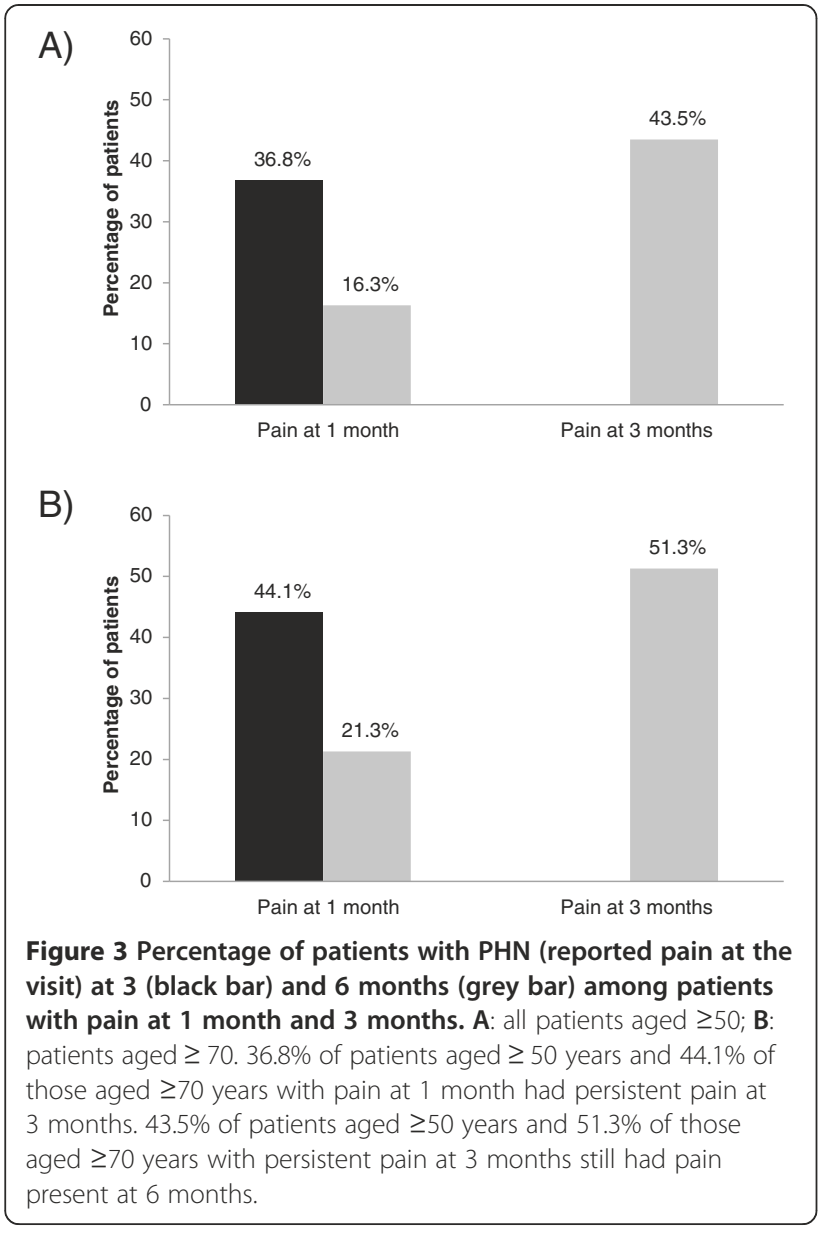

reported an age-related increase in the percentage of patients with HZ-associated pain. The percentage of patients with PHN observed in HEROES was lower than the 40\% assumed for the sample size estimation. Although we recruited fewer than the original target of 500 patients, we had data for the planned 400 patients needed to estimate the percentages of patients with PHN at 3 and 6 months with good precision. PHN can last for several months to several years but in this study we followed the patients for six months. This may have led to an underestimation of the true clinical burden of PHN. In this study, general practitioners recruited the participants. In Italy patients need to be referred for specialist care by their general practitioner, and even when they use private healthcare to consult a specialist directly, they have to report to their general practitioner for reimbursement of prescriptions via the national health system. Hence are results are likely to be generalizable in healthcare systems requiring referral for specialist appointments.

The presence of $>50$ vesicles, a VAS score $\geq 3$ and being male were identified as variables that were associated with PHN at three months. The first two variables have been reported previously to be associated with a higher risk of developing PHN at three months suggesting that PHN is probably linked to more severe acute episodes of HZ [16]. However, other studies have either not reported any gender differences or have reported an increased risk in women, unlike our study. This may be due to differences in study methodology or, perhaps, in our study, women underestimated the level of their pain. It is also conceivable that there are more women in the older-age groups, so that there is confounding with age [40].

Most of the patients (91.5\%) in HEROES received antivirals as recommended, which is similar to that reported in other studies $[15,16,22]$. In contrast, only $23 \%$ of our patients were reported as receiving pain therapy. This could be due to the low disease severity or because in Italy the most frequent pain therapies, i.e. paracetamol and NSAIDs are available without prescription and were, therefore, not reported by the physicians.

With the predicted ageing of the European population in the coming decades, the number of people affected by $\mathrm{HZ}$ and its related complications, including PHN, can

Table 4 Predictive factors for persistentHZ-associated pain - results from multivariate regression

\begin{tabular}{|c|c|c|c|c|}
\hline Explanatory variable & Level of explanatory variable & $P$ value & OR estimates & $95 \% \mathrm{Cl}$ \\
\hline More than 50 vesicles & Yes vs no & 0.0091 & 2.595 & $1.267-5.314$ \\
\hline VAS score $\geq 3$ at V0 & Yes vs no & 0.0278 & 4.599 & 1.181-17.907 \\
\hline Gender & Male vs female & 0.0481 & 2.017 & $1.006-4.042$ \\
\hline Presence of allodynia & Yes vs no & 0.1039 & 1.812 & $0.005-3.710$ \\
\hline MCS-12 score & Continuous variable & 0.2858 & 0.982 & $0.951-1.015$ \\
\hline Age & Continuous variable & 0.5420 & 1.011 & $0.977-1.046$ \\
\hline Associated diseases* & Yes vs no & 0.6162 & 1.226 & $0.553-2.719$ \\
\hline PCS-12 score & Continuous variable & 0.6853 & 0.992 & $0.952-1.033$ \\
\hline Rash area (lumbar dermatome) & Yes vs no & 0.8261 & 1.111 & $0.435-2.836$ \\
\hline
\end{tabular}

*Presence of diabetes, chronic cardiovascular disease or chronic respiratory diseases.

Hosmer and Lemeshow goodness-of-fit test: $p=0.4098$.

MCS-12 score: SF12 mental component summary score; PCS-12 score: SF12 physical component summary score.

The variables that were significantly predictive of pain present at 3 months were having more than 50 vesicles at V0, VAS score $\geq 3$ at V0 and being male. 
also be expected to increase [41]. Preventive strategies, including vaccines, are thought to play an important role in the promotion of healthy ageing. Immunosenescence is reported to increase the risk of developing $\mathrm{HZ}$ due to an impaired T -cell-mediated immunity. In the Shingles Prevention Study, a live-attenuated Oka/Merck strain VZV vaccine was shown to reduce the incidences of $\mathrm{HZ}$ and PHN significantly, compared with placebo [35]. This vaccine is indicated in the EU for adults aged $\geq 50$ years; in 2013, the UK started a shingles vaccination program targeting those aged between 70 and 79 years.

\section{Conclusions}

These data suggest that there is an important burden of disease in the elderly due to HZ. There is a need for interventions that can prevent and reduce the burden of HZ to help improve the quality of life of the elderly. These data may be useful as baseline epidemiology data for the assessment of the impact of the VZV vaccine in Italy, after its implementation.

\section{Abbreviations}

eCRF: Electronic case report form; EU: European Union; GP: General practitioner; HEROES: HERpes zoster Outcome: Epidemiological Study; HZ: Herpes zoster; ICD: International Classification of Disease; MCS-12: Mental component score; PCS-12: Physical component score; PHN: Post-herpetic neuralgi; QoL: Quality of life; SAS: Statistical Analysis System; SF-12: Short form-12 (quality of life questionnaire); UK: United Kingdom; US: United States; VAS: Visual analogue scale; VZV: Varicella zoster virus.

\section{Competing interests}

Helene Bricout and Emilia Perinetti: work for Sanofi Pasteur MSD who commercialise the vaccine Zostavax ${ }^{\oplus}$, produce by MSD, in Europe. Paolo Marchettini: has been an advisor for Sanofi Pasteur MSD.

Pietro Ragni: has received grants from Sanofi Pasteur MSD for being a member of advisory boards over the last five years.

Carla Maria Zotti: declared no conflicts of interest.

Giovanni Gabutti: over the last five years, has received grants from Sanofi Pasteur MSD, GlaxoSmithKline Biologicals SA, Novartis, Crucell/Janssen and Pfizer for taking part in advisory boards, expert meetings, being a speaker or an organiser of congresses / conferences, and acting as investigator in clinical trials; is a member of an Independent Data Monitoring Committee of a phase 3 clinical trial on an herpes zoster vaccine.

Antonio Volpi: over the last five years, has received grants from Sanofi Pasteur MSD and GlaxoSmithKline for advisory boards, expert meetings, and acting as an investigator in clinical trials is as a member of an Independent Data Monitoring Committee of a phase 3 clinical trial on a varicella vaccine Elisabetta Franco: has received research grants paid by Sanofi Pasteur MSD and Pfizer to her institution; has received payments from GlaxoSmithKline Biologicals SA, Pfizer, Janssen and Sanofi Pasteur MSD for travel and accommodation for meeting attendance.

\section{Authors' contributions}

All authors contributed to the drafting and review of the manuscript and validated the final version. HB: Study follow-up, data management and data analysis, study report, interpretation of the results, writing of the manuscript outline. EP: Study coordination and review of all study documents. PM: Protocol development, critical review and interpretation of the data. PR: Conception, design and planning of the study. CMZ: Recruitment of investigators in Turin LHUs and assistance to the MMG during the study. AV: Conception, design and planning of the study, critical review and interpretation of the data. EF: Conception, design and planning of the study, critical review and interpretation of the data. GG: Conception, design and planning of the study, critical review and interpretation of the data. All authors read and approved the final manuscript.

\section{Acknowledgements}

The authors take full responsibility for the contents of this manuscript but would like to thank Margaret Haugh, MediCom Consult (supported by Sanofi Pasteur MSD) for her assistance in the preparation of the manuscript. The authors would like to thank all the study investigators: local health unit (LHU) of Asti: G. De Maria, C. Torello, C. Nuti; LHU of Bologna: A. Guerra, L. Gaggioli, M. Casadei, A.L. Lalli, A. Matrà; LHU of Brindisi: G.A. D'Urso, P. Caliandro, F. Siliberto, G. Gatti, G. Mastro, B. Giordano, A. Suma; LHU of Bussolengo (VR): S. Mantovani, A. Severi, A.M. Oliva, A. Panzino, C. Zanotto; LHU of Carbonia (CI): E. Piras, L. Lisci, S. Massa, R.Rovere, B. Putzolu; LHU of Catanzaro: G.G. Arturi, C.L. Rossi, A. De Felice, F. Bellini, V. Capilupi, A Battaglia, F. Vasta, F. Moniaci; LHU of Ferrara: S. Gamberoni, C. Roveggio, M. Gennari, B. Fabbri; LHU of Grosseto: G. Guidoni, A. Salvetti, T. Iocca, M. Zuccarello, G. Bellumori, L. Steri; LHU of Lecce: S. Miglietta, V. Ferrari, A. Chiriatti, I. Colona, A. Andrani; LHU of Milano: M.B. Pagani, V. Bova, D. Ciaci, C. Pirovano, S. Croci, G. Grandinetti, F. Marrali, I. Mussi, E. Noia, R. Palmieri, P. Rodriguez, N. Santoro, G. Scavone, U. Binda; LHU of Napoli/5: A. Apicella, G. Perasole, D. De Riso, A. Frunzio, A. Varone, G. Arpaia; LHU of Pescara: W. Del Ponte, S. Di Marco, M. Palombo, C. Carunchio, O. Di Domizio, M. Buffone; LHU of Ragusa: B. La TerraBella, G. Dezio, S. Dipasquale, R. Zelante, G. DiGiacomo, M. Iudice, S. Bennardo, G. Ferro; LHU of Roma/C: A. Nobile, G. Piccolelli, C. Prono, M. Pitrolo, P. LeVoci, P. Marchetti, C. Di Mauro, G. Salvi; LHU of Roma/H: A. Nigro, M. Mazzilli, G. Riggio, C. Villari, F. LaManna, G. Cerroni, V. Gatti, E. Grimaldi, F. De Ligio, A. Ottaviani; LHU of Teramo: G. De Berardinis, G. D'Isidoro, M. Di Paolantonio, U. Scardecchia, O. Di Andrea; LHU of Torino/1: E. Bianco, S. Panèro, P. Fracchia, M. M. Di Sario, P. Lapi, M. Grasso, A. Pugliese, A. Lambarelli; LHU of Treviso: A.Moro, G. Simeone, P. Tullio; LHU of Varese: L. Felloni, G. Ronzi, F. Blesi, F. Colombo, M. Passamonti, W. Colombo, M.E. Perego, T. Dell'Arciprete, F. Baranzini; LHU of Verona: A.Tosi, H. Mehrabi, L. Menegazzi, A. Guido, E. Mascalzoni, R. Trespidi; LHUof Vibo Valentia: A. D'Amico, A. Burello, C. Zavettieri, G. Spanarello, A. Teramo, N.B. Arena.

The authors would also like to thank Pierrel Research (Milano, Italy) for project management, study monitoring, data management and statistical analyses, and the following Sanofi Pasteur MSD employees for their contributions to the study: Raffaele Di Marzo (study design), Laurence Serradell-Vallejo (study management) and Perrine Bertet (data management).

\section{Author details}

${ }^{1}$ Epidemiological Department, Sanofi Pasteur MSD, Lyon, France. ${ }^{2}$ Medical \& Scientific Department, Sanofi Pasteur MSD, Rome, Italy. ${ }^{3}$ Pain Medicine Center, Hospital San Raffaele of Milan, Milan, Italy. ${ }^{4}$ Local Health Authority for Reggio Emilia, Emilia Romagna, Italy. ${ }^{5}$ Department of Public Health and Paediatrics, University of Turin, Turin, Italy. ${ }^{6}$ Department of Medical Sciences, University of Ferrara, Ferrara, Italy. ${ }^{7}$ Department of Clinical Sciences, University of Rome Tor Vergata, Rome, Italy. ${ }^{8}$ Department of Biomedicine and Prevention, University of Rome Tor Vergata, Rome, Italy. ${ }^{9}$ Pain Pathophysiology and Therapy, University School of Italian Switzerland, Manno, Lugano, Switzerland.

\section{Received: 18 March 2014 Accepted: 18 November 2014}

\section{.}

\section{References}

1. Johnson RW: Herpes zoster and postherpetic neuralgia. Expert Rev Vaccines 2010, 9(3 Suppl):21-26.

2. Kimberlin DW, Whitley RJ: Varicella-zoster vaccine for the prevention of herpes zoster. N Engl J Med 2007, 356(13):1338-1343.

3. Johnson RW, Wasner G, Saddier P, Baron R: Postherpetic neuralgia: epidemiology, pathophysiology and management. Expert Rev Neurother 2007, 7(11):1581-1595.

4. Arvin A: Aging, immunity, and the varicella-zoster virus. N Engl J Med 2005, 352(22):2266-2267

5. Johnson RW: Herpes Zoster and Postherpetic Neuralgia: a review of the effects of vaccination. Aging Clin Exp Res 2009, 21(3):236-243.

6. Schmader K: Herpes zoster in older adults. Clin Infect Dis 2001 32(10):1481-1486.

7. Hicks LD, Cook-Norris RH, Mendoza N, Madkan V, Arora A, Tyring SK: Family history as a risk factor for herpes zoster: a case-control study. Arch Dermatol 2008, 144(5):603-608.

8. Thomas SL, Hall AJ: What does epidemiology tell us about risk factors for herpes zoster? Lancet Infect Dis 2004, 4(1):26-33. 
9. Centers for Disease Control and Prevention: Prevention of herpes zoster. Recommendations of the Advisory Committee on Immunization Practices (ACIP). MMWR 2008, 57:1-30.

10. Arvin AM: Varicella-zoster virus. Clin Microbiol Rev 1996, 9(3):361-381.

11. Meister W, Neiss A, Gross G, Doerr H, Hobel W, Malin J, von Essen J, Reimann B, Witke C, Wutzler P: Demography, symptomatology, and course of disease in ambulatory zoster patients. A physician-based survey in Germany. Intervirology 1998, 41(6):272-277.

12. Drolet $M$, Brisson M, Schmader KE, Levin MJ, Johnson R, Oxman MN, Patrick D, Blanchette C, Mansi JA: The impact of herpes zoster and postherpetic neuralgia on health-related quality of life: a prospective study. CMAJ 2010, 182(16):1731-1736.

13. Volpi A, Gatti A, Pica F, Bellino S, Marsella LT, Sabato AF: Clinical and psychosocial correlates of post-herpetic neuralgia. J Med Virol 2008, 80(9):1646-1652.

14. Hempenstall K, Nurmikko TJ, Johnson RW, A'Hern RP, Rice AS: Analgesic therapy in postherpetic neuralgia: a quantitative systematic review. PLOS Med 2005, 2(7):e164.

15. Dworkin RH, Johnson RW, Breuer J, Gnann JW, Levin MJ, Backonja M, Betts RF, Gershon AA, Haanpaa ML, McKendrick MW, Nurmikko TJ, Oaklander AL, Oxman MN, Pavan-Langston D, Petersen KL, Rowbotham MC, Schmader KE, Stacey BR, Tyring SK, Van Wijck AJ, Wallace MS, Wassilew SW, Whitley RJ: Recommendations for the management of herpes zoster. Clin Infect Dis 2007, 44(Suppl 1):S1-S26

16. Bouhassira D, Chassany O, Gaillat J, Hanslik T, Launay O, Mann C, Rabaud C, Rogeaux O, Strady C: Patient perspective on herpes zoster and its complications: an observational prospective study in patients aged over 50 years in general practice. Pain 2012, 153(2):342-349.

17. Forbes HJ, Thomas SL, Smeeth L, Langan SM: Prescription of antiviral therapy after herpes zoster in general practice: who receives therapy? $\mathrm{Br}$ $J$ Gen Pract 2012, 62(605):e808-e814.

18. Opstelten W, van Essen GA, Moons KG, van Wijck AJ, Schellevis FG, Kalkman CJ, Verheij TJ: Do herpes zoster patients receive antivirals? A Dutch National Survey in General Practice. Fam Pract 2005, 22(5):523-528.

19. Parruti G, Tontodonati M, Rebuzzi C, Polilli E, Sozio F, Consorte A, Agostinone A, Di Masi F, Congedo G, D'Antonio D, Granchelli C, D'Amario C, Carunchio C, Pippa L, Manzoli L, Volpi A: Predictors of pain intensity and persistence in a prospective Italian cohort of patients with herpes zoster: relevance of smoking, trauma and antiviral therapy. BMC Med 2010, 8:58.

20. Li Q, Chen N, Yang J, Zhou M, Zhou D, Zhang Q, He L: Antiviral treatment for preventing postherpetic neuralgia. Cochrane Database Syst Rev 2009 (2):Cd00686

21. Pinchinat $S$, Cebrian-Cuenca AM, Bricout H, Johnson RW: Similar herpes zoster incidence across Europe: results from a systematic literature review. BMC Infect Dis 2013, 13:170

22. Mick G, Hans G: Postherpetic neuralgia in Europe: the scale of the problem and Outlook for the future. J Clin Gerontol Geriat 2013, 4(4):102-108.

23. di Luzio PU, Arpinelli F, Visona G: Herpes zoster and its complications in Italy: an observational survey. J Infect 1999, 38(2):116-120.

24. Di Legami V, Gianino MM, Ciofi degli Atti M, Massari M, Migliardi A, Tomba GS, Zotti C: Epidemiology and costs of herpes zoster: background data to estimate the impact of vaccination. Vaccine 2007, 25(43):7598-7604

25. Gialloreti LE, Merito M, Pezzotti P, Naldi L, Gatti A, Beillat M, Serradell L, di Marzo R, Volpi A: Epidemiology and economic burden of herpes zoster and post-herpetic neuralgia in Italy: a retrospective, population-based study. BMC Infect Dis 2010, 10:230.

26. Gabutti G, Serenelli C, Cavallaro A, Ragni P: Herpes zoster associated hospital admissions in Italy: review of the hospital discharge forms. Int $J$ Environ Res Public Health 2009, 6(9):2344-2353.

27. Guidelines for the classification and conduct of pharmaceutical observation studies [Linee guida per la classificazione e conduzione degli studi osservazionali sui farmaci] [http://www.agenziafarmaco.gov.it/ allegati/det 20marzo2008.pdf]

28. Good Epidemiological Practice (GEP) [http://ieaweb.org/goodepidemiological-practice-gep/]

29. Ware J Jr, Kosinski M, Keller SD: A 12-item short-form health survey: construction of scales and preliminary tests of reliability and validity. Med Care 1996, 34(3):220-233.
30. Coplan PM, Schmader K, Nikas A, Chan IS, Choo P, Levin MJ, Johnson G, Bauer M, Williams HM, Kaplan KM, Guess HA, Oxman MN: Development of a measure of the burden of pain due to herpes zoster and postherpetic neuralgia for prevention trials: adaptation of the brief pain inventory. J Pain 2004, 5(6):344-356

31. Cebrian-Cuenca AM, Diez-Domingo J, San-Martin-Rodriguez M, Puig-Barbera J, Navarro-Perez J, Herpes Zoster Research Group of the Valencian C: Epidemiology and cost of herpes zoster and postherpetic neuralgia among patients treated in primary care centres in the Valencian community of Spain. BMC Infect Dis 2011, 11:302.

32. Scott FT, Leedham-Green ME, Barrett-Muir WY, Hawrami K, Gallagher WJ, Johnson R, Breuer J: A study of shingles and the development of postherpetic neuralgia in East London. J Med Virol 2003, 70(Suppl 1):S24-S30.

33. Mick G, Gallais JL, Simon F, Pinchinat S, Bloch K, Beillat M, Serradell L, Derrough T: Burden of herpes zoster and postherpetic neuralgia: incidence, proportion, and associated costs in the french population aged 50 or over. Rev Epidemiol Sante Publique 2010, 58(6):393-401.

34. SF-12 health survey: Italian version [Questionario sullo stato di salute SF-12 Versione italiana) [http://crc.marionegri.it/qdv/downloads/SF12\% 20Manuale.pdf]

35. Oxman MN, Levin MJ, Johnson GR, Schmader KE, Straus SE, Gelb LD, Arbeit RD, Simberkoff MS, Gershon AA, Davis LE, Weinberg A, Boardman KD, Williams HM, Zhang JH, Peduzzi PN, Beisel CE, Morrison VA, Guatelli JC, Brooks PA, Kauffman CA, Pachucki CT, Neuzil KM, Betts RF, Wright PF, Griffin MR, Brunell P, Soto NE, Marques AR, Keay SK, Goodman RP: A vaccine to prevent herpes zoster and postherpetic neuralgia in older adults. $N$ Engl J Med 2005, 352(22):2271-2284

36. Whitley RJ, Volpi A, McKendrick M, Wijck A, Oaklander AL: Management of herpes zoster and post-herpetic neuralgia now and in the future. J Clin Virol 2010, 48(Suppl 1):S20-S28.

37. Cebrian-Cuenca AM, Diez-Domingo J, Rodriguez MS, Puig-Barbera J, Navarro-Perez J: Epidemiology of herpes zoster infection among patients treated in primary care centres in the Valencian community (Spain). BMC Fam Pract 2010, 11:33.

38. Gauthier A, Breuer J, Carrington D, Martin M, Remy V: Epidemiology and cost of herpes zoster and post-herpetic neuralgia in the United Kingdom. Epidemiol Infect 2009, 137(1):38-47.

39. Schiffner-Rohe J, Jow S, Lilie HM, Koster I, Schubert I: Herpes zoster in Germany. A retrospective analyse of SHI data [Herpes zoster in Deutschland. Eine retrospektive Analyse von GKV-Daten]. MMW Fortschr Med 2009, 151(Suppl 4):193-197.

40. Johnson RW, Dworkin RH: Treatment of herpes zoster and postherpetic neuralgia. BMJ 2003, 326(7392):748-750.

41. Eurostat: Active Ageing and Solidarity Between Generations. A Statistical Portrait of the European Union 2012. 12th edition. Luxembourg: Publications Office of the European Union; 2012.

doi:10.1186/s12879-014-0637-6

Cite this article as: Bricout et al:: Burden of herpes zoster-associated chronic pain in Italian patients aged 50 years and over (20092010): a GP-based prospective cohort study. BMC Infectious Diseases 2014 14:637.

\section{Submit your next manuscript to BioMed Central and take full advantage of:}

- Convenient online submission

- Thorough peer review

- No space constraints or color figure charges

- Immediate publication on acceptance

- Inclusion in PubMed, CAS, Scopus and Google Scholar

- Research which is freely available for redistribution 